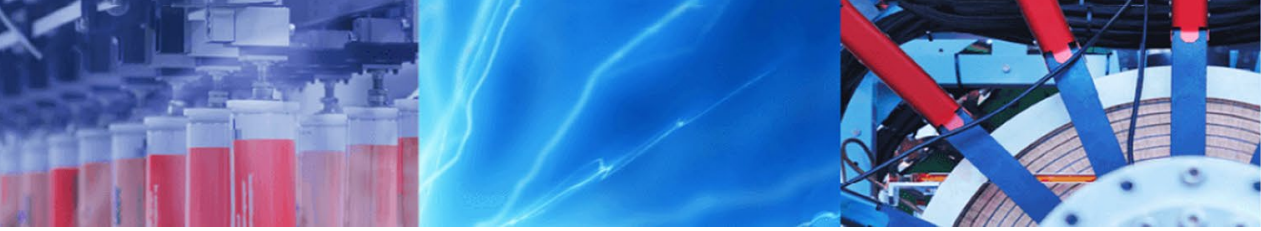

Research Article

\title{
Preparation, characterization and cost analysis of activated biochar and hydrochar derived from agricultural waste: a comparative study
}

\author{
Endashaw Workie Yihunu ${ }^{1} \cdot$ Mengist Minale $^{2} \cdot$ Sisay Abebe ${ }^{3} \cdot$ Ma Limin $^{1}$
}

(c) Springer Nature Switzerland AG 2019

\begin{abstract}
Utilization of low-cost, abundant and biomaterials is highly recommended for sustainable environment protection. This study presents a comparative analysis on the preparation, characterization and cost analysis of the novel activated biochar (BTS) and activated hydrochar (HTS). Teff (Eragrostis tef) straw was used as a precursor for producing BTS and HTS through pyrolysis and hydrothermal carbonization process, respectively. Both chars were further activated using $30 \mathrm{wt} \% \mathrm{H}_{3} \mathrm{PO}_{4}$ for $3 \mathrm{~h}$ activation time. The physicochemical properties of both chars were compared by different characterization techniques including BET, FTIR, XRD, SEM, and TGA. Briefly, BTS exhibited heterogeneous surface structures and comparatively larger specific surface area $\left(627.7 \mathrm{~m}^{2} / \mathrm{g}\right)$ than that of HTS $\left(43.8 \mathrm{~m}^{2} / \mathrm{g}\right)$ with the smooth coalesced carbon layer and dull surface edges. The XRD analysis revealed the amorphous character of HTS which is dominantly composed of $\mathrm{AlPO}_{4}$, whilst indicating BTS to be the crystalline structure with the very trivial amount of impurities. The oxygen-containing functional groups increased for HTS in comparison to BTS. Thermogravimetric analysis showed that HTS exhibited better thermal behaviors. Estimated costs incurred in the production of the HTS were found to be cheaper than compared to BTS. Overall, the experiment result suggested that Teff straw could have the potential for producing a low cost activated chars.
\end{abstract}

Keywords Teff (Eragrostis tef) · Biochar · Hydrochar · Pyrolysis · Hydrothermal carbonization (HTC)

\section{Introduction}

The sustainable material research gives a primary concern on two major criteria's, such as rising environmental concerns and the need for cost-effective competitive products. Arguably, the use of biomass as a source of the carbonaceous product has recently become popular due to their availability, feasibility and biodegradable in nature $[1,2]$. They have a potential to be converted to solid, liquid and gaseous products. However, the implementation of the low-cost pathway to recycle biomasses would additionally represent a way to sequester a significant amount of $\mathrm{CO}_{2}$ creating a material benefit as well [3]. Biomass contains a minimal amount of sulfur, nitrogen, and ash which make them more environment-friendly [4]. It is not only the carbon-neutral sources, but it has the potential applications in energy storage [3], water purification [5, 6], hydrogen storage [7], and catalysis [4, 8]. In recent years, various indigenous biomass including agricultural wastes has been used enormously as a sustainable precursor to produce hydrochar, biochar, and activated carbon [4].

Although biomasses can be converted to a periodic porous carbon network using different techniques, the two thermochemical treatments: hydrothermal carbonization and pyrolysis process have been mainly practiced. Pyrolysis is the thermal process which converts biomass

$\triangle$ Ma Limin, liminmma@163.com |'State Key Laboratory of Pollution Control and Resources Reuse, Tongji University, Shanghai 200092, People's Republic of China. ${ }^{2}$ College of Environmental Science and Engineering, Tongji University, Shanghai 200092 , People's Republic of China. ${ }^{3}$ School of Environmental Science and Engineering, Suzhou University of Science and Technology, Suzhou, People's Republic of China. 
into liquid, gaseous and solid fuels that can be performed through rapid heating [9]. Biochar is the stable carbonaceous by-product produced by pyrolysis of organic materials such as plant residues, agricultural byproducts, algae and other biomasses [10].

Biomaterials can also be widely applied for a different purpose after their surface introduced the functional groups and carbons via a simple technical route. Typically, this process occurs under the aqueous medium of organic materials and relatively low temperature referred to as hydrothermal carbonization (HTC) [11]. The resulting solid carbon products, hydrochar, generally exhibit uniform chemical and structural properties as well as very high and tunable content of oxygen-containing functional groups. Notwithstanding that both chars (biochar and hydrochar) can be used for a similar purpose, they significantly differ from each other in terms of their physical and chemical properties [12] Hydrochar is quite hydrophobic, friable, and more energy dense while biochar is a pyrogenic black carbon which exhibits high porosity and attraction sites. In addition, the yield of hydrochar is about 70 to $80 \%$, which is higher than biochar [13].

One of the biggest disadvantages in the application of biomasses is their high energy requirement per low quality. However, catalysts may increase the reaction rate and reduce energy consumption per unit of volume treated. In this manner, the issues of carbon synthesis under sustainable conditions was as of late returned to and actualized by a few terms, where catalytic treatment of biomass relatively in the mild condition provided bulk, mesoporous or nanostructured chars. Moreover, the suitability of both biochar and hydrochars can be improved through chemical activation via $\mathrm{HCl}[14], \mathrm{ZnCl}_{2}$ [1], $\mathrm{H}_{3} \mathrm{PO}_{4}$ [2], $\mathrm{KOH}$ [15], etc., since they provide high surface area and high porosity [16]. In this regard, several literature works have reported the performance of various agricultural wastes such as rice husk [17], Perennial grass [18], wheat straw [19], etc. as a sustainable precursor for the production of activated char. Activation through $\mathrm{H}_{3} \mathrm{PO}_{4}$ is, however, most preferable as compared to other activation chemicals due to its mild reaction conditions, less hazardous after-effect on the environment and also gives high adsorbent yield [20]. Li et al. [21] reported that the acid ( $15 \mathrm{wt} \% \mathrm{H}_{3} \mathrm{PO}_{4}$ ) assisted hydrochar prepared from bamboo sawdust have rough surfaces with BET surface areas of $17.08 \mathrm{~m}^{2} / \mathrm{g}$ and oxygenrich functional groups.

However, the production of activated char at low concentration of activation agent and low energy input is still required to be solved. Further, the comparative analysis on the preparation route (under similar activation agent, concentration and time), feasibility (cost) and characterization of activated biochar and hydrochar derived from a new agricultural waste-Teff (Eragrostis tef) straw have not yet been reported. Teff (E. tef) is a fine stemmed, tufted annual cereal crop native to Ethiopia with the largest share of farmlands. After collecting the edible part, it provides a large amount of byproduct (wastes) that we used to make activated biochar and hydrochar. Tadesse et al. [22] reported the removal capacity of $\mathrm{Cd}$ (II) from aqueous solution using a natural Teff straw as a sorbent material.

This paper has focused solely on the preparation and characterization of a novel activated biochar and hydrochar prepared from Teff ( $E$. tef) straw has investigated. To understand which char type would favorably respond to the chemical activation process, both adsorbents were chemically activated under similar activation agent $\left(\mathrm{H}_{3} \mathrm{PO}_{4}\right)$, concentration (30 wt $\left.\%\right)$ and time (3 h). To identify their physicochemical properties; morphology, texture, functional groups, crystallinity, and thermal behavior are well characterized. Besides, the cost spent to produce on lab scale per mass of each activated carbon were analyzed.

\section{Materials and methods}

\subsection{Adsorbents preparation}

Phosphoric acid $\left(\mathrm{H}_{3} \mathrm{PO}_{4}\right)$ purchased from Sigma-Aldrich Companies were of analytical grade. Teff straw was cut into smaller pieces, washed thoroughly, dried, crushed well and sieved. Subsequently, chemical activation using phosphoric acid was done by modifying a method as demonstrated [20]. Briefly, $8 \mathrm{~g}$ of prepared Teff straw was impregnated with $30 \mathrm{wt} \% \mathrm{H}_{3} \mathrm{PO}_{4}$ solution and stirred at room temperature for $12 \mathrm{~h}$. After the supernatant was removed, the remaining wet solid precursors were directly transferred to a tubular furnace to be pyrolyzed at $450{ }^{\circ} \mathrm{C}$ for $3 \mathrm{~h}$ in the presence of oxygen. This is based on a review of literature that reported that the application of low pyrolysis temperature [23] and slow pyrolysis process [24] obtained a higher char yield having higher pore volume. The activated char was taken out after the heat was cooled to room temperature and then washed by distilled water till the effluent becomes neutral $\mathrm{pH}$. The resulted char was dried at $110^{\circ} \mathrm{C}$ for $6 \mathrm{~h}$ and then assigned as activated Teff straw biochar (BTS).

For hydrochar, $8 \mathrm{~g}$ of prepared Teff straw was mixed with $30 \mathrm{wt} \% \mathrm{H}_{3} \mathrm{PO}_{4}$ solution in a $100 \mathrm{ml}$ Teflon lined autoclave reactor. The reactor was heated at $190^{\circ} \mathrm{C}$ for $3 \mathrm{~h}$, and then cooled naturally to room temperature. The solid product was separated by vacuum filtration, washed and dried as the procedure used for BTS. The final result was noted as activated Teff straw hydrochar (HTS). 


\subsection{Physicochemical characterization}

Characterizing the physicochemical properties of biochar and hydrochar, in turn, determine the best application of these materials [9]. Characterization methods may range from simple conventional analyses, that allow measuring basic properties like surface morphology, functional groups, crystal structure, thermal stability, etc., to more advanced ones. In this study, the surface morphology of both products was observed by scanning electron microscope (SEM, JSM-7800F) at 20 and $10 \mu \mathrm{m}$ magnification. The presence of functional groups on their surfaces was confirmed by Fourier Transform Infrared Spectroscopy (FTIR, Nicolet IS 10) in a wavelength of 400 to $4000 \mathrm{~cm}^{-1}$. $\mathrm{X}$-ray diffractometer (XRD, Bruker D8-Advance) with Cu-Ka radiation $(\lambda=1.5418 \AA, 40 \mathrm{kV})$ was used to characterize the crystalline pattern of both chars. The textural feature of both chars was determined by $\mathrm{N}_{2}$ adsorption-desorption isotherms at $77 \mathrm{~K}$ using ASAP (Micrometrics 2460 ) surface area and porosity analyzer. Subsequently, the surface area and average pore size were calculated by the Brunauer-Emmett-Teller (BET) and
Barret-Joyner-Halenda (BJH) method, respectively. Thermogravimetric (TGA) analysis with derivative thermogravimetry (DTG) curve was conducted on the thermal analyzer (SDT Q600) from 30 to $900^{\circ} \mathrm{C}$ with a heating rate of $10^{\circ} \mathrm{C} / \mathrm{min}$ in an inert atmosphere $\left(\mathrm{N}_{2}, 100 \mathrm{ml} / \mathrm{min}\right)$.

\section{Results and discussion}

\subsection{Physicochemical properties of the adsorbent}

\subsubsection{Morphological properties}

SEM images in Fig. 1 depicted the structural differences of HTS and BTS at different magnification. The BTS displayed unevenly distributed scattershot pores, rough and irregular structure while HTS dominantly exhibited a smooth coalesced carbon layer with stacked alignment. The reason for BTS is due to the lignin and cellulose structures of the sample was extremely damaged and/or disappeared during pyrolysis. During the HTC process, the acidic medium has gradually seeped into the amorphous cellulose and
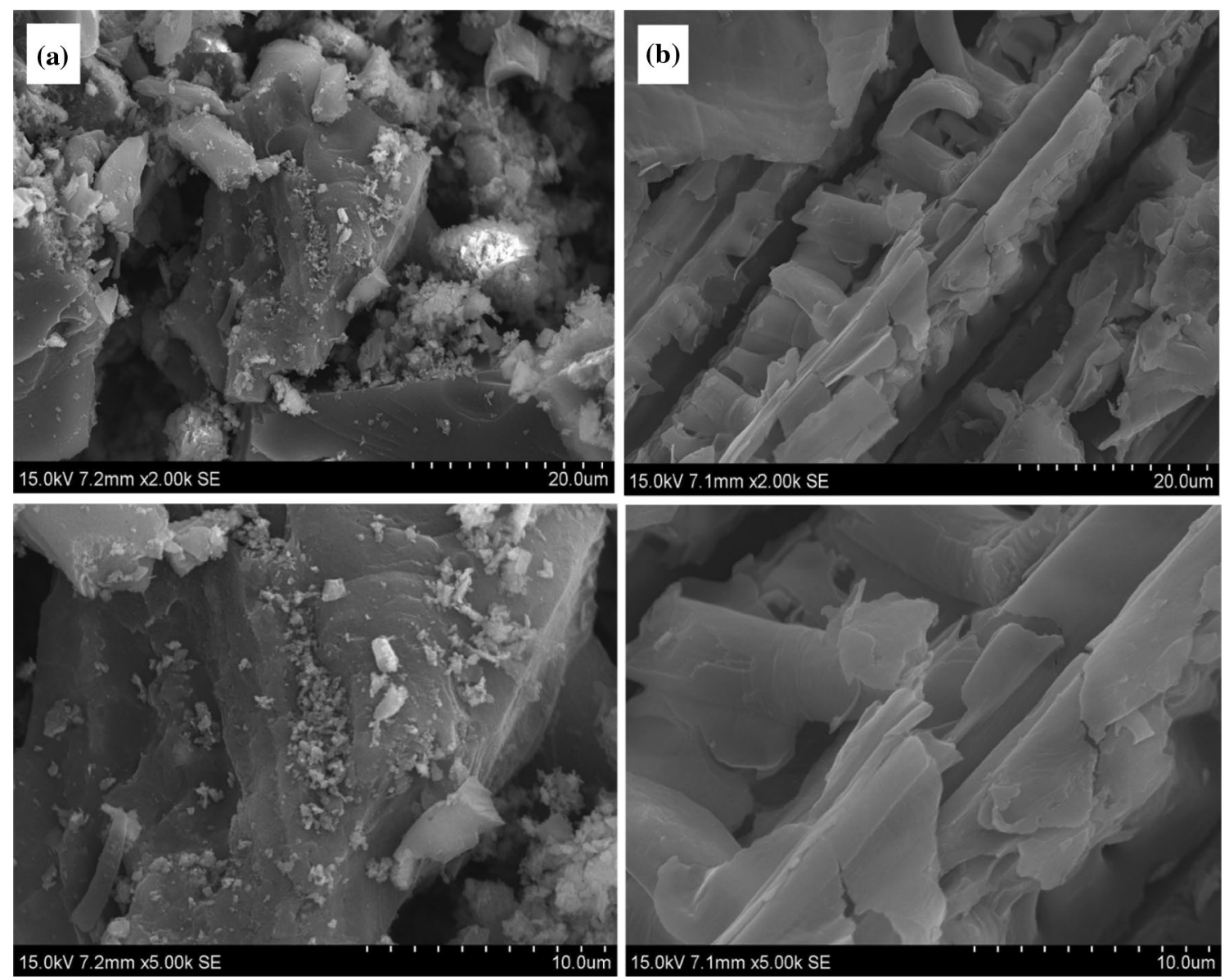

Fig. 1 SEM images of BTS (a) and HTS (b) 

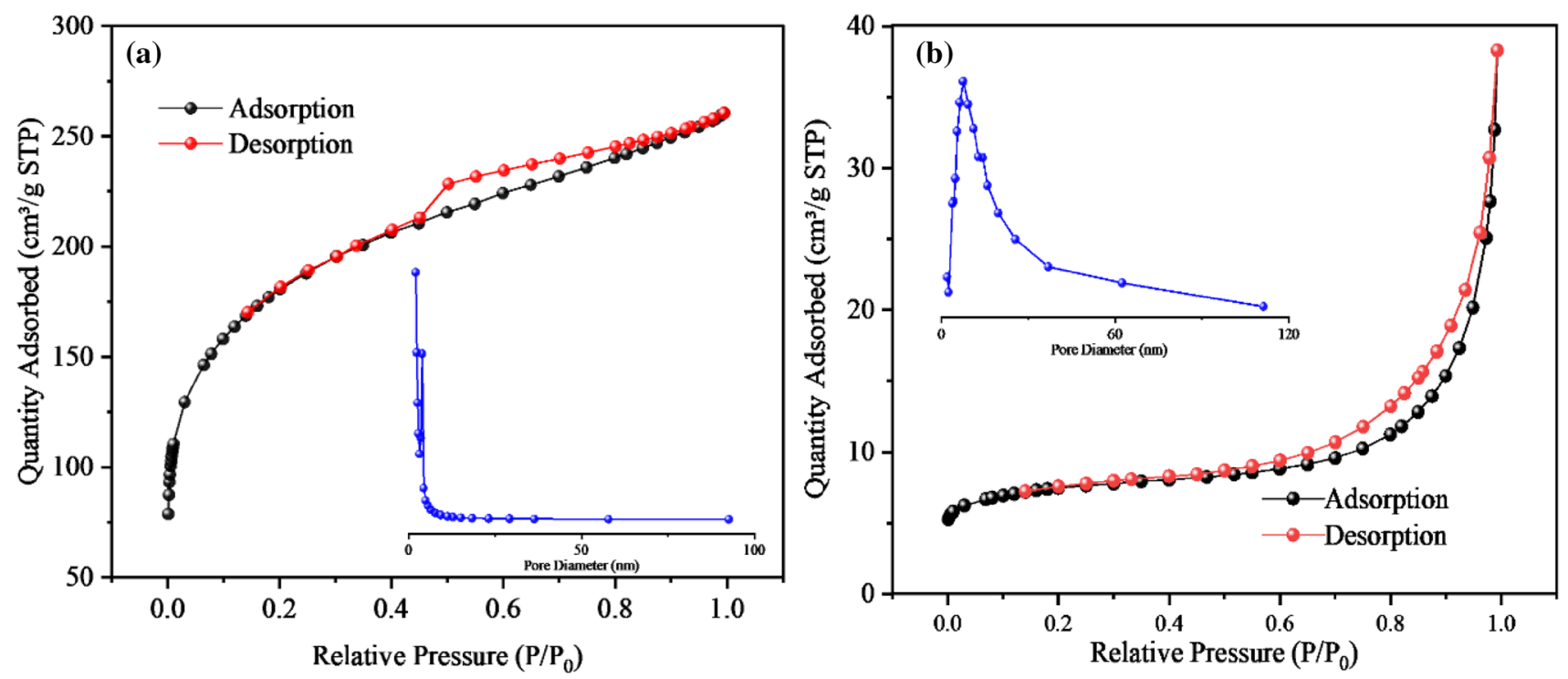

Fig. 2 The $\mathrm{N}_{2}$ adsorption-desorption isotherms of BTS (a) and HTS (b) (insert: pore size distribution)

Table 1 Specific surface area, total pore volume and pore size of BTS and HTS

\begin{tabular}{llll}
\hline Adsorbents & $\mathrm{S}_{\text {BET }}\left(\mathrm{m}^{2} \mathrm{~g}^{-1}\right)$ & $\mathrm{V}_{\mathrm{T}}\left(\mathrm{m}^{-3} \mathrm{~g}^{-1}\right)$ & $\mathrm{D}_{\mathrm{av}}(\mathrm{nm})$ \\
\hline BTS & 627.76 & 0.388 & 2.48 \\
HTS & 43.8 & 0.087 & 9.43 \\
\hline
\end{tabular}

some soluble segments of lignin of straw resulting in cracked and disrupt the cellulose chain [2]. Further, it can be seen good dispersion of water molecule into the matrix and the fiber did not agglomerate during hydrolysis resulting in HTS exhibited higher interfacial adhesion and smooth heterogeneous surfaces with dull surface edges.

\subsubsection{Textural behaviors}

The $\mathrm{N}_{2}$ adsorption-desorption isotherms of HTS and BTS analyzed (Fig. 2). According to IUPAC classification, BTS displayed a combined isotherm type I and IV with $\mathrm{H} 4$ hysteresis loop, explaining the presence of a narrow slit-like microporous and mesoporous surface gain through multilayer adsorption followed by capillary condensation.

By contrast, HTS exhibited isotherm type IV with $\mathrm{H} 3$ hysteresis loop, indicating staged adsorption on mesopores. Its hysteresis loop revealed loose assemblages of the plate-like structure at which the capillary condensation taking place to fill and withdraw $\mathrm{N}_{2}$ molecules on those mesopores. It is noteworthy that the BET specific surface area $\left(\mathrm{S}_{\mathrm{BET}}\right)$ and total pore volume $\left(\mathrm{V}_{\mathrm{T}}\right)$ of $\mathrm{HTS}$ are far less than BTS (Table 1). Hence, BTS is expected to further facilitate especially for the adsorption of micro-pollutant

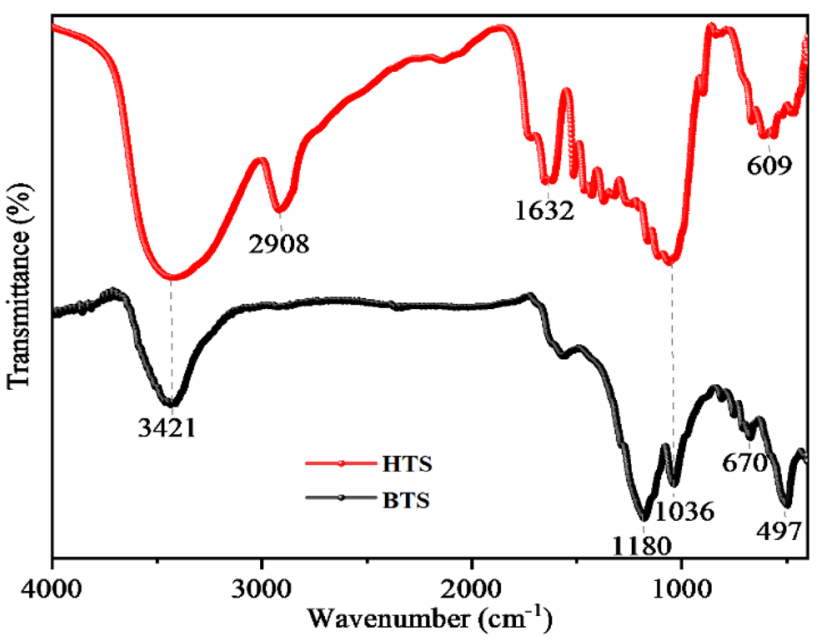

Fig. 3 FTIR spectra of BTS and HTS

through having such favorable morphology which is accessible to adsorbate molecules in a given size and shape than HTS. The linkages of phosphate and phosphate ester with lignocellulose may encourage the expansion of the structure, whereby the voids volume was protected $[20,25]$. Further, the average pore diameter $\left(D_{a v}\right)$ shows larger for HTS than BTS.

\subsubsection{The chemical structure}

The functionalities of both chars studied by FTIR spectra are shown in Fig. 3. The peaks observed on both chars at $3421 \mathrm{~cm}^{-1}$ and $1036 \mathrm{~cm}^{-1}$ are assigned to stretching vibrations of $\mathrm{O}-\mathrm{H}[26]$ and sulfonic group, respectively. 
Compared to HTS, the peak observed at $2908 \mathrm{~cm}^{-1}$ derived from the asymmetric aliphatic saturated $\mathrm{C}-\mathrm{H}$ group [27] and $1632 \mathrm{~cm}^{-1}$ indicating $C=C$ stretching vibrations and its derived carbons [28] are not observed in BTS. Rather, BTS shows an intensity reduction of such groups due to lignin removal during the pyrolysis treatments. The bending vibration peaks of the water molecules at $1180 \mathrm{~cm}^{-1}$ representing aromatic $\mathrm{C}-\mathrm{O}-\mathrm{C}$ Stretching from cellulose. Some weak bands were also observed in both adsorbents between 700 and $490 \mathrm{~cm}^{-1}$, indicating the presence of $\mathrm{C}-\mathrm{C}$ stretching.

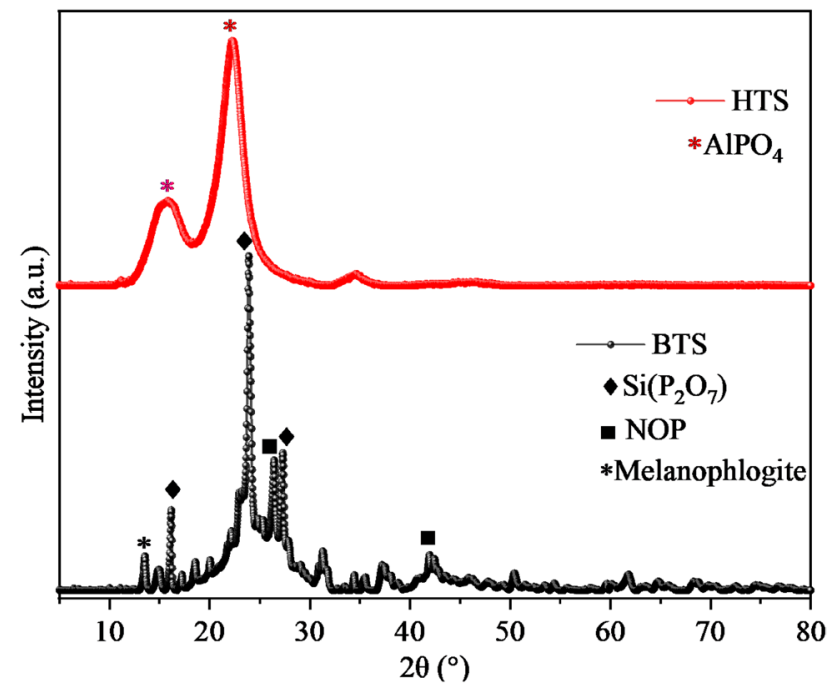

Fig. 4 XRD Patterns of BTS and HTS

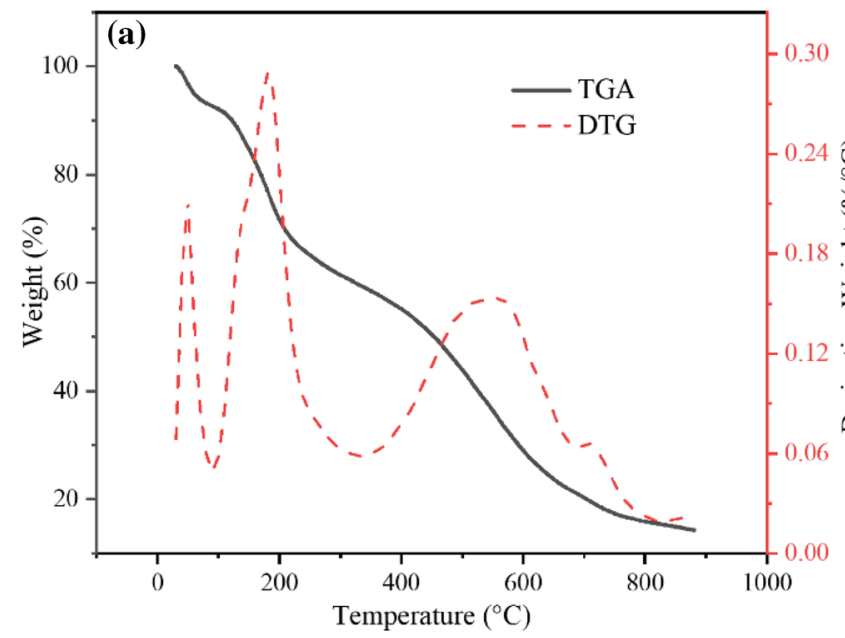

\subsubsection{Crystal structure}

Phase analysis of HTS and BTS and their XRD patterns are shown in Fig. 4. The diffraction patterns of BTS at 16.2 and $27.3^{\circ}$ shows the planes of $\mathrm{Si}\left(\mathrm{P}_{2} \mathrm{O}_{7}\right)$ while 42 and $26.5^{\circ}$ show the plane of cristobalite-type phosphorus oxonitride (NOP) [29]. Those peaks also revealed the crystalline carbonaceous structure of BTS. The sharp and intense peak at $24^{\circ}$ is due to the enlargement of crystalline size and further development of pores. The extra slight peaks appeared at $20.1631 .35,51.2$ and $62.5^{\circ}$ are associated with randomly existed SiC crystal structure of a short-ranged order in graphene oxide layers. The two broad peaks of HTS shown at around 14.4 and $26^{\circ}$ are signifying the amorphous $\mathrm{AIPO}_{4}$ phase [30].

\subsubsection{The thermal properties}

The thermogravimetry analysis (TGA) and derivative thermogravimetry (DTG) curve of BTS and HTS are shown in Fig. 5. The weight loss of both adsorbents in the temperature range from 30 to $250^{\circ} \mathrm{C}$, ascribed to the surfacebound water and moisture release (dehydration). The steep and gradual weight loss (49\%) for HTS occurred from 250 to $545{ }^{\circ} \mathrm{C}$ and the major weight loss (about $76 \%$ ) for BTS took place from 250 to $700^{\circ} \mathrm{C}$ is attributed mainly to the decomposition of cellulose and lignin [23]. The final weight loss (86.07\%) of BTS remained constant above $700{ }^{\circ} \mathrm{C}$ while the total weight loss $(91.79 \%)$ for HTS remained constant after the temperature reached $545^{\circ} \mathrm{C}$. As it can be seen the DTG curve from Fig. 5, the peak weight loss for BTS took place at $250^{\circ} \mathrm{C}$ while the maximum weight loss for $\mathrm{HTS}$ occurred at $300^{\circ} \mathrm{C}$. Biomass with the high volatile matter has the highest conversion, in comparison to biomass with high fixed carbon. Thus,

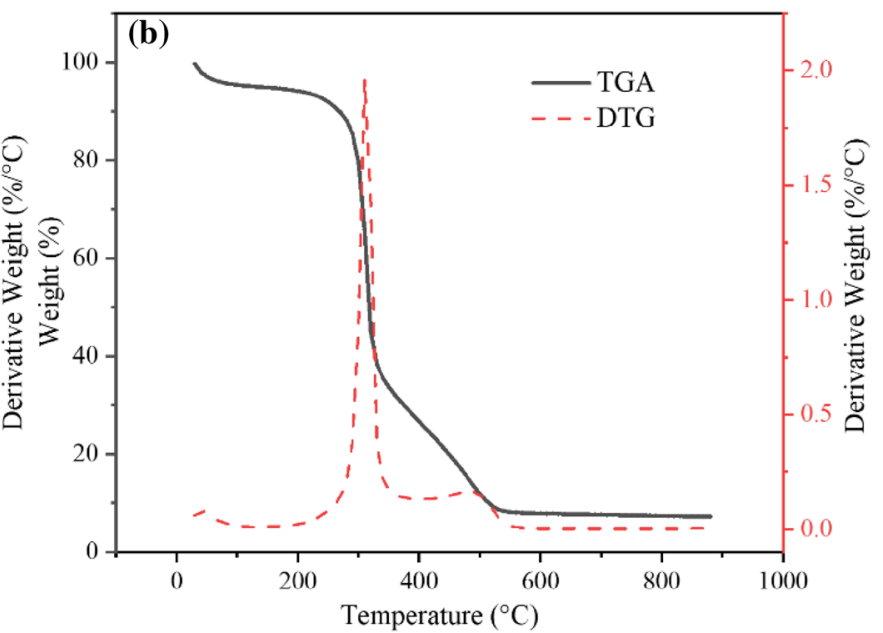

Fig. 5 TGA and DTG curve of BTS (a) and HTS (b) 
biomass with higher volatile fraction may be suitable for the production of carbonized materials [31].

\subsection{Cost estimation}

The cost analysis is very important to determine whether the whole production process of the activated char is feasible or not. The cost influencing factors like the availability of raw material, treatment conditions, and other process requirements should be analyzed/estimated $[32,33]$. Accordingly, considering the raw material (Teff straw) and oven cost is free since the oven heat can be replaced by sunlight, the remaining cost mainly for activation chemicals (i.e. phosphoric acid) and electric power was calculated. The total cost spent to produce $1 \mathrm{~kg}$ of BTS and $1 \mathrm{~kg}$ HTS at lab scale is $24.33 \mathrm{RMB}$ and 19.1 RMB, respectively. As shown in Table 2, the cost of BTS preparation is a bit higher due to higher power consumption whereas the production cost of HTS was comparatively cheaper since it has been treated under low heat energy. However, this cost would be lower when it will be produced commercially on a large pilot scale. The cost analysis of BTS and HTS recommends that the activated char preparation process using
Teff straw as a raw input is quite cost-effective among which HTS can be used as the best one.

In addition, Table 3 presents the comparative reports of this study with the previous works done by researchers using different materials and activation conditions. It can be seen that the total cost spent to produce biomass-based char varied depending on the preparation process. For instance, Chakraborty et al. [32] prepared porous activated biochar using sugarcane bagasse as raw material and $85 \% \mathrm{H}_{3} \mathrm{PO}_{4}$ as activating agent. Although the production cost is almost equal to the current study, they employed a highly concentrated activation agent which may cause an ill effect on environmental safety.

\section{Conclusions}

The Teff straw has demonstrated a better performance to produce activated char (hydrochar and biochar). Both BTS and $\mathrm{HTS}$ are produced under minimum activation condition (low $\mathrm{H}_{3} \mathrm{PO}_{4}$ concentration and temperature) and at nearly long activation time. The SEM analysis indicated that the surface morphology of BTS. The specific surface
Table 2 The detail cost estimation of BTS and HTS

\begin{tabular}{|c|c|c|c|c|}
\hline \multirow[t]{2}{*}{ Preliminary } & \multirow[t]{2}{*}{ Details } & \multirow[t]{2}{*}{ Break up } & \multicolumn{2}{|c|}{ Cost (RMB) } \\
\hline & & & BTS & HTS \\
\hline & Raw material & Freely available & 0.0 & 0.0 \\
\hline & Drying & Sunlight (instead) & 0.0 & 0.0 \\
\hline & Crushing & Electric crusher & 1.81 & 1.81 \\
\hline \multicolumn{5}{|l|}{ Activation } \\
\hline & Carbonization/pyrolysis (heat) & $\begin{array}{l}\text { Hour } \times \text { unit } \times \text { Unit } \\
\text { cost }=3 \times 1 \times \text { cost per } \\
\text { max heat level }\end{array}$ & 6.67 & 2.23 \\
\hline & Ortho phosphoric acid $\left(\mathrm{H}_{3} \mathrm{PO}_{4}\right)$ & $\begin{array}{l}\text { Cost per volume } \\
(\mathrm{ml}) \times \text { unit } \times \text { concentra- } \\
\text { tion }=52.8 \times 1 \times 0.3\end{array}$ & 15.86 & 15.86 \\
\hline Total cost & & & 24.34 & 19.1 \\
\hline
\end{tabular}

Table 3 Comparative analysis with other biomass-based chars reported on literatures

\begin{tabular}{|c|c|c|c|c|c|c|}
\hline Raw materials & Mode of treatment & Activation agent & $\begin{array}{l}\text { Activation } \\
\text { concentration }\end{array}$ & $\begin{array}{l}\text { BET-Specific sur- } \\
\text { face area }\left(\mathrm{m}^{2} / \mathrm{g}\right)\end{array}$ & Cost/kg (RMB) & References \\
\hline Sugarcane bagasse & Pyrolysis & $\mathrm{H}_{3} \mathrm{PO}_{4}$ & $85 \%$ & 557 & 24.86 & {$[32]$} \\
\hline Parthenium hysterophorus & Pyrolysis & $\mathrm{NaOH}$ & - & 308 & 18.24 & {$[33]$} \\
\hline Alumina & Pyrolysis & $\mathrm{H}_{2} \mathrm{SO}_{4}$ & $98 \%$ & 87.44 & - & {$[34]$} \\
\hline Bamboo sawdust & HTC & $\mathrm{H}_{3} \mathrm{PO}_{4}$ & $15 \%$ & 17.08 & & {$[21]$} \\
\hline Hazelnut shell & Pyrolysis & $\mathrm{C}_{6} \mathrm{H}_{3} \mathrm{O}_{7}$ & - & 60 & - & {$[10]$} \\
\hline \multirow[t]{2}{*}{ Corn straw } & Pyrolysis & - & - & 327.7 & - & {$[5]$} \\
\hline & HTC & - & - & 6.37 & - & \\
\hline \multirow[t]{2}{*}{ Teff straw } & Pyrolysis & $\mathrm{H}_{3} \mathrm{PO}_{4}$ & $30 \%$ & 627.76 & 24.33 & This study \\
\hline & HTC & $\mathrm{H}_{3} \mathrm{PO}_{4}$ & $30 \%$ & 43.8 & 19.1 & \\
\hline
\end{tabular}


area of BTS is comparable with previously reported natural chars but less compared to synthetic carbon. The FTIR spectra confirmed the presence of more oxygen and carbon-containing functional groups on the surface of HTS. The BTS performed a multistage decomposition with relatively stable intermediates, indicates the temperature limit of stability of reactants and intermediate products. Although the total cost spent on the preparation of HTS is a bit cheaper as compared for BTS, while both are still low-cost products. Hence, it can be concluded that Teff straw can be considered as an alternative low-cost precursor manufacturing of activated char for light-weight applications.

Acknowledgements This work was supported by the Key Program of China (2018YFC1803103, 2017ZX07206) and National Natural Science Foundation of China (No. 21377098).

\section{Compliance with ethical standards}

Conflict of interest The authors declare that they have no conflict of interest.

\section{References}

1. Zhang H, Yan Y, Yang L (2010) Preparation of activated carbon from sawdust by zinc chloride activation. Adsorption 16:161166. https://doi.org/10.1007/s10450-010-9214-5

2. Lei $Y$, Su H, Tian $F$ (2018) A novel nitrogen enriched hydrochar adsorbents derived from salix biomass for $\mathrm{Cr}(\mathrm{VI})$ adsorption. Sci Rep 8:1-9. https://doi.org/10.1038/s41598-018-21238-8

3. Antonietti M, Zhao L, Titirici MM (2014) Sustainable carbon hybrid materials made by hydrothermal carbonization and their use in energy applications. Nanocarbon Inorganic Hybrids Next Gener Compos Sustain Energy Appl. https://doi. org/10.1515/9783110269864.201

4. Zheng Y, Tao L, Yang X et al (2018) Study of the thermal behavior, kinetics, and product characterization of biomass and lowdensity polyethylene co-pyrolysis by thermogravimetric analysis and pyrolysis-GC/MS. J Anal Appl Pyrolysis 133:185-197. https ://doi.org/10.1016/j.jaap.2018.04.001

5. Liu Y, Ma S, Chen J (2018) A novel pyro-hydrochar via sequential carbonization of biomass waste: preparation, characterization and adsorption capacity. J Clean Prod 176:187-195. https://doi. org/10.1016/j.jclepro.2017.12.090

6. Kazi TG, Brahman KD, Baig JA, Afridi HI (2018) A new efficient indigenous material for simultaneous removal of fluoride and inorganic arsenic species from groundwater. J Hazard Mater 357:159-167. https://doi.org/10.1016/j.jhazmat.2018.05.069

7. Ni M, Leung DYC, Leung MKH, Sumathy K (2006) An overview of hydrogen production from biomass. Fuel Process Technol 87:461-472. https://doi.org/10.1016/j.fuproc.2005.11.003

8. Alhumade H, da Silva JCG, Ahmad MS et al (2019) Investigation of pyrolysis kinetics and thermal behavior of Invasive Reed Canary (Phalaris arundinacea) for bioenergy potential. J Anal Appl Pyrolysis 140:385-392. https://doi.org/10.1016/j. jaap.2019.04.018

9. Taskin E, de Castro Bueno C, Allegretta I et al (2019) Multianalytical characterization of biochar and hydrochar produced from waste biomasses for environmental and agricultural applications. Chemosphere. https://doi.org/10.1016/j.chemo sphere.2019.05.204

10. Jain A, Balasubramanian R, Srinivasan MP (2016) Hydrothermal conversion of biomass waste to activated carbon with high porosity: a review. Chem Eng J 283:789-805. https://doi. org/10.1016/j.cej.2015.08.014

11. Xu Q, Qian Q, Quek A et al (2013) Hydrothermal carbonization of macroalgae and the effects of experimental parameters on the properties of hydrochars. ACS Sustain Chem Eng 1:1092-1101. https://doi.org/10.1021/sc400118f

12. Workie $\mathrm{YE}, \mathrm{Yu} \mathrm{H}$, Junhe $\mathrm{W}$ et al (2019) A comparative study on defluoridation capabilities of biosorbents: isotherm, kinetics, thermodynamics, cost estimation and regeneration study. Environ Eng Res. https://doi.org/10.4491/eer.2019.097

13. Chen J, Zhang L, Yang G et al (2017) Preparation and characterization of activated carbon from hydrochar by phosphoric acid activation and its adsorption performance in prehydrolysis liquor. BioResources 12:5928-5941. https://doi.org/10.15376/ biores.12.3.5928-5941

14. Qian WC, Luo XP, Wang X et al (2018) Removal of methylene blue from aqueous solution by modified bamboo hydrochar. Ecotoxicol Environ Saf 157:300-306. https://doi.org/10.1016/j. ecoenv.2018.03.088

15. Tran HN, Lee CK, Nguyen TV, Chao HP (2018) Saccharidederived microporous spherical biochar prepared from hydrothermal carbonization and different pyrolysis temperatures: synthesis, characterization, and application in water treatment. Environ Technol (United Kingdom) 39:2747-2760. https://doi. org/10.1080/09593330.2017.1365941

16. Jain A, Xu C, Jayaraman S et al (2015) Mesoporous activated carbons with enhanced porosity by optimal hydrothermal pretreatment of biomass for supercapacitor applications. Microporous Mesoporous Mater 218:55-61. https://doi.org/10.1016/j. micromeso.2015.06.041

17. Goswami R, Kumar M (2018) Removal of fluoride from aqueous solution using nanoscale rice husk biochar. Groundw Sustain Dev 7:446-451. https://doi.org/10.1016/J.GSD.2017.12.010

18. Saikia R, Goswami R, Bordoloi N et al (2017) Removal of arsenic and fluoride from aqueous solution by biomass based activated biochar: optimization through response surface methodology. J Environ Chem Eng 5:5528-5539. https://doi.org/10.1016/J. JECE.2017.10.027

19. Kumar Yadav A, Abbassi R, Gupta A, Dadashzadeh M (2013) Removal of fluoride from aqueous solution and groundwater by wheat straw, sawdust and activated bagasse carbon of sugarcane. Ecol Eng 52:211-218. https://doi.org/10.1016/j.ecole ng.2012.12.069

20. Yakout SM, Sharaf El-Deen G (2016) Characterization of activated carbon prepared by phosphoric acid activation of olive stones. Arab J Chem 9:S1155-S1162. https://doi.org/10.1016/j.arabj c.2011.12.002

21. Li Y, Meas A, Shan S et al (2018) Hydrochars from bamboo sawdust through acid assisted and two-stage hydrothermal carbonization for removal of two organics from aqueous solution. Bioresour Technol 261:257-264. https://doi.org/10.1016/j.biort ech.2018.03.108

22. Tadesse B, Teju E, Megersa N (2015) The Teff straw: a novel lowcost adsorbent for quantitative removal of $\mathrm{Cr}(\mathrm{VI})$ from contaminated aqueous samples. Desalin Water Treat 56:2925-2936. https://doi.org/10.1080/19443994.2014.968214

23. Chowdhury ZZ, Karim MZ, Ashraf HA, Khalid K (2016) Influence of carbonization temperature on physicochemical properties of biochar derived from. BioResources 11:3356-3372. https://doi. org/10.15376/biores.11.2.3356

24. Üner O, BayrakY (2018) The effect of carbonization temperature, carbonization time and impregnation ratio on the properties of 
activated carbon produced from Arundo donax. Microporous Mesoporous Mater 268:225-234. https://doi.org/10.1016/j. micromeso.2018.04.037

25. Chakraborty P, Banerjee S, Kumar S et al (2018) Elucidation of ibuprofen uptake capability of raw and steam activated biochar of Aegle marmelos shell: isotherm, kinetics, thermodynamics and cost estimation. Process Saf Environ Prot 118:10-23. https://doi. org/10.1016/j.psep.2018.06.015

26. Hongtao L, Shuxia L, Hua Z et al (2018) Comparative study on synchronous adsorption of arsenate and fluoride in aqueous solution onto MgAIFe-LDHs with different intercalating anions. RSC Adv 8:33301-33313. https://doi.org/10.1039/c8ra05968c

27. Heilmann SM, Davis HT, Jader LR et al (2010) Hydrothermal carbonization of microalgae. Biomass Bioenergy 34:875-882. https ://doi.org/10.1016/j.biombioe.2010.01.032

28. Sano H, Omine K, Prabhakaran M et al (2018) Groundwater fluoride removal using modified mesoporous dung carbon and the impact of hydrogen-carbonate in borehole samples. Ecotoxicol Environ Saf 165:232-242. https://doi.org/10.1016/j. ecoenv.2018.09.001

29. Bykov M, Baykova E, Dyadkin V et al (2015) Crystal structures of cristobalite-type and coesite-type PON redetermined on the basis of single-crystal X-ray diffraction data. Acta Crystallogr Sect E Crystallogr Commun 71:1325-1327. https://doi. org/10.1107/s205698901501899x

30. Graetsch HA (2003) Thermal expansion and thermally induced variations of the crystalstructure of $\mathrm{AlPO}_{4}$ low crystobalite.
Neues Jahrbuch für Mineralogie Monatshefte 7:289-301. https ://doi.org/10.1127/0028-3649/2003/2003-0289

31. Dhyani V, Bhaskar T (2018) A comprehensive review on the pyrolysis of lignocellulosic biomass. Renew Energy 129:695-716. https://doi.org/10.1016/j.renene.2017.04.035

32. Chakraborty P, Show S, Banerjee S, Halder G (2018) Mechanistic insight into sorptive elimination of ibuprofen employing bi-directional activated biochar from sugarcane bagasse: performance evaluation and cost estimation. J Environ Chem Eng 6:5287-5300. https://doi.org/10.1016/j.jece.2018.08.017

33. Mondal S, Aikat K, Halder G (2016) Biosorptive uptake of ibuprofen by chemically modified Parthenium hysterophorus derived biochar: equilibrium, kinetics, thermodynamics and modeling. Ecol Eng 92:158-172. https://doi.org/10.1016/j.ecole ng.2016.03.022

34. Kumari U, Behera SK, Meikap BC (2018) A novel acid modified alumina adsorbent with enhanced defluoridation property: kinetics, isotherm study and applicability on industrial wastewater. J Hazard Mater 365:868-882. https://doi.org/10.1016/j. jhazmat.2018.11.064

Publisher's Note Springer Nature remains neutral with regard to jurisdictional claims in published maps and institutional affiliations. 